\section{Giorgio Zanchin}

Received: 20 July 2007

Accepted in revised form: 26 July 2007

Published online: 24 September 2007

\title{
Reply to G.F. d'Acquapendente tabulae pictae on the nervous system
}

Sir,

We do not think appropriate to afford here the second part of Riva's criticism, which makes reference to a paper by one of us (G.Z.) not printed in JHP [1]. However, although unfavourably impressed by the terms and general tone used in the above letter, we will answer the first part of it.

Riva's paper was not quoted since it does not represent, in our opinion, an accurate systematic anatomical and historical study of the tabulae pictae. Indeed, as the Author writes, his paper boasts to report "in synthesis the anatomical priorities present in all the tabulae pictae, including those on the De Anatomia Capitis Cerebri Nervorum described by Zanchin and De Caro". This quite difficult task the tabulae pictae on human anatomy exceed the number of one hundred is accomplished within a short paper (six pages, including bibliography, whose just one on the nervous system) by a mere anatomical listing, missing any iconography or argue to support and demonstrate the Author's opinion [2].

In conclusion, despite Riva's paper, we maintain that "...neither descriptions of the morphological aspects nor analysis of the research contents of the tabulae pictae have ever been carried out....", at least if we have to deal with a scientific presentation. For these reasons, our article is not "false and mendacious", as Riva writes: simply we did not quote his paper because we wanted to avoid a useless polemic [3]. Indeed, we disagree from its superficial comment on this outstanding accomplishment by d'Acquapendente, and from its assertive approach, including that on the Syluius's lateral tissure, without giving any element to allow readers' criticism: exactly the opposite of what was the didactic and scientific scope of the tabulae pictae.

Giorgio Zanchin Department of Neurosciences, Headache Center University of Padua Medical School Via Giustiniani 2, I-35121 Padua, Italy

Tel.: +39-049-8213626

Fax.: +39-049-8272335

E-mail: giorgio.zanchin@unipd.it

Raffaele De Caro

Department of Human Anatomy and Physiology

University of Padua Medical School Padua, Italy 


\section{References}

1. Zanchin G (2004) De Anatomia Capitis Cerebri Nervorum. Le tabulae pictae di Fabrici sul sistema nervoso. In: Rippa Bonati M, Pardo-Tomas J (Eds) Il teatro dei corpi. Le pitture colorate d'anatomia di Girolamo Fabrici d'Acquapendente. Mediamed, Milan, pp 235-245
2. Riva A (2004) Priorità anatomiche nelle Tabulae Pictae. In: Rippa Bonati M, Pardo-Tomas J (Eds) Il teatro dei Corpi. Le Pitture Colorate d'anatomia di Fabrici d'Acquapendente. Mediamed, Milano: pp 147-152
3. Zanchin G, De Caro R (2006) The nervous system in colours: the tabulae pictae of G. F. d'Acquapendente (ca. 1533-1619) J Headache and Pain $7: 360-366$ 